\title{
Dual-fuzzy based MPPT for dual-load operation with photovoltaic SEPIC converter
}

\begin{abstract}
In this paper, a dual load operation with dual maximum power point tracking (MPPT) for standalone photovoltaic (PV) system is introduced. This work investigates performance of PV system with dual load operation and variable irradiance by using proposed fuzzy based dual MPPT. The algorithm together with PV module of Kyocera KD210GH-2PU connected to PV SEPIC dc-dc converter was simulated in MATLAB-Simulink. Its performance has been compared with perturb and observe $(\mathrm{P} \& \mathrm{O})$. Analysis on the effect of input power and output voltage at the load side when duty cycle and irradiance change have been discussed. From the results and analysis, dual fuzzy MPPT with dual load shows that maximum power can be obtained at lower irradiance by using higher resistance load and during high irradiance, lower resistance is needed in order to achieve maximum power. Different irradiance levels requires different values of resistance load to achieve maximum power and these only can be done using dual fuzzy MPPT with dual loads.
\end{abstract}

Keyword: Dual load; Fuzzy logic; MPPT; Photovoltaic; SEPIC dc-dc converter 